\title{
Aflatoxin in raw peanut kernels marketed in Malaysia.
}

\begin{abstract}
The occurrence of af latoxin in eighty-four samples of raw peanut kernels which are randomly collected from Malaysian super- markets was examined. Analysis for af latoxin was performed by solvent extraction and immunoaffinity clean-up followed by the determination using high performance liquid chromatography equipped with post-column photochemical reactor for enhanced detection and f luorescence detector. A detection limit of $0.01-0.09 \mathrm{ng} / \mathrm{mL}$ and a quantification limit of $0.04-0.30 \mathrm{ng} / \mathrm{mL}$ were obtained. The af latoxin concentrations ranged from not detected to $97.28 \mathrm{ng} / \mathrm{g}$ in all samples investigated. About $78.57 \%$ of the samples were contaminated with af latoxin, of which $10.71 \%$ exceeded the maximum tolerable limit of $15 \mathrm{ng} / \mathrm{g}$ set by the Codex. Average recoveries of the af latoxin analysis were acceptable which were in the range of $74.85 \pm 8.83 \%$ for AFG2 at the concentration of $0.15 \mathrm{ng} / \mathrm{mL}$ and $103.91 \pm 6.45 \%$ for AFB2 at the concentration of 0.15 $\mathrm{ng} / \mathrm{mL}$. The average daily intake estimated for total af la- toxins was $10.69 \mathrm{ng} / \mathrm{kg}$ body weight. There was a significant difference $(\mathrm{P}<0.05)$ in af latoxin content between brands and locations.
\end{abstract}

Keyword: Aflatoxin; Peanut; Food safety; HPLC with fluorescence detection; Immunoaffinity clean-up. 